\title{
Effectiveness of Full Can Exercise and Eccentric Training on Quality of Life in Patients with Shoulder Impingement Syndrome
}

\author{
Kalpana Jain \\ Assistant Professor, Physiotherapy Department, Career College, Bhopal
}

DOI: https://doi.org/10.52403/ijhsr.20220225

\begin{abstract}
Background: The article is about effectiveness of full can exercise in shoulder impingement syndrome. The study was aimed to compare the effect of full can exercise and eccentric training along with conventional physiotherapy management in patients with shoulder impingement syndrome (SIS). The pain occurs because of compression and mechanical abrasion of the subacromial structures against the anterior undersurface of the acromion and coracoacromial ligament, especially during elevation of the arm. The supraspinatus tendon is usually the most affected structure in SIS due to its location just under the coracoacromial ligament. The aim of our study was to compare the effectiveness of full can exercise and eccentric training on quality of life in patients with SIS.

Materials and Methods: In the study, both group A (full can exercise group) and group B (eccentric training group) consisted of 15 patients each with SIS. The participants of both the groups received conventional physiotherapy along with the specific exercises assigned to their groups. Treatment was given in the supervision of physiotherapist for 30 minutes a session, 5 days a week, for total 4 weeks duration in the both groups. Pre and Post assessment was done using Oxford Shoulder Score (OSS).

Result: Before intervention, both the groups demonstrated similar OSS scores. After therapy, there was a statistically significant improvement in both the groups. There was a significant difference between the two groups in OSS scores after the exercise program.
\end{abstract}

Conclusion: The study result reveals that full can exercise is more beneficial than eccentric training.

Keywords: Full can exercise, Eccentric training, Shoulder impingement syndrome.

\section{INTRODUCTION}

Shoulder joint is a most complex joint of human body. The shoulder joint is made of the clavicle, scapula, and humerus and is a complicated blend of three joints; the glenohumeral joint, the acromioclavicular joint and the sternoclavicular joint. ${ }^{1}$ A complete painless shoulder arc depends upon normal functioning of these joints, proper positioning of the humeral head in the glenohumeral fossa, and a normal functional relationship of surrounding shoulder muscles and structures. ${ }^{14}$ Shoulder impingement syndrome (SIS) is one of the most common causes of shoulder pain ${ }^{7,10,11}$.The pain occurs because of compression and mechanical abrasion of the subacromial structures against the anterior undersurface of the acromion and coracoacromial ligament, especially during elevation of the $\mathrm{arm}^{8}$.

The cause of SIS includes increased subacromial loading, trauma, overhead activity, rotator cuff overload and muscle imbalance, glenohumeral instability, long head of biceps tendon laxity, glenoid labral lesion, posterior capsule tightness and trapezius paralysis ${ }^{14}$.Symptoms of SIS may include pain, inflammation, decreased ROM, strength and functional activity. It is observed that SIS is associated with anterior 
instability that results in posterior tightness and pain occurs in arc between $70^{\circ}$ to $120^{\circ}$ of abduction ${ }^{13}$. Management of SIS involves conventional physical therapy including electrotherapy (ultrasound, cryotherapy and electrical stimulation) to reduce pain, strengthening exercises of rotator cuff muscles. $^{22}$

In SIS, supraspinatus muscle is most vulnerable muscle to impingement due to its mechanical compression between coracoacromial arch and the greater tuberosity of humerus during flexion and abduction of shoulder. The subacromial space is reduced as the humerus moves superiorly either because of weakness or from the injury to rotator cuff $^{24}$. Full can exercise is a great choice to improve muscular strength of supraspinatus and thus relieving pain due to impingement. Exercise involving shoulder abduction in the scapular plane with the shoulder in external rotation has been termed as the "full can" exercise ${ }^{24}$. Full Can Exercise helps to improve both the strength and endurance of supraspinatus muscle. It acts by maintaining the scapula in retracted position throughout the exercise and also activates the scapula stabilizers. Scapular retraction produces more force and also minimizes the activation of deltoid muscle along with supraspinatus that results in prevention of decrease in subacromial space and superior humeral head migration ${ }^{25}$.

Other useful exercise regime for reliving shoulder pain is "eccentric training" which involves contraction of supraspinatus muscle during deceleration load while the muscle or tendon is in stretched position. Eccentric exercise produces high forces and induces remodeling response ${ }^{23}$. It has been proposed that in eccentric loading, three basic principle work; during eccentric loading length of tendon increases, when tendon is in pre-stretched position and less strain is placed on tendon during movement, the strength of tendon increases by progressive increase in the load, thus the speed of contraction also increases which results in increase in the force developed by the tendon or muscle. Eccentric exercise exposes the tendon to a greater load as compared to concentric exercise; ${ }^{23}$, however its effectiveness has not yet been compared with full can exercise.

Previous researches have shown that shoulder pain significantly affects the quality of life. Shoulder pain is assessed by Oxford Shoulder Score (OSS) ${ }^{30}$, which is a specific questionnaire. It is sensitive to assess quality of life, clinical change and is also easy to complete ${ }^{26}$.

Till date researches have been done to evaluate various interventions for shoulder impingement syndrome. The present study has been proposed to evaluate the effect of full can exercise and eccentric training on quality of life in patients with shoulder impingement syndrome. We hypothesized that there would be a significant difference between the effect of full can exercise and eccentric training on quality of life in patients with SIS.

The aim of our study was to compare the effectiveness of full can exercise and eccentric training on quality of life in patients with SIS. The objectives of the study were to: (i)observe the effect of full can exercise along with conventional physiotherapy, (ii) observe the effect of eccentric training along with conventional physiotherapy and (iii) compare the effect of full can exercise and eccentric training on quality of life in patients with SIS.

\section{METHODOLOGY}

The study was approved by Institutional Ethical Committee. This study was a pre post design experimental study. 30 patients (both male and female subjects) diagnosed with shoulder impingement syndrome between the age 25 to 45 years were included in this study, which were divided randomly (lottery method) into 2 groups i.e. Group A and Group B, each comprising of 15 subjects. Group A 
received full can exercise along with conventional therapy and group B received eccentric training along with conventional therapy.

Subjects were selected for the study if they had: (i) a positive sign of Neer's impingement and/ or Hawkins Kennedy test; (ii) painful abduction in the Arc of $70^{\circ}$ to $120^{\circ}$; (iii) tenderness over greater tuberosity of the humerus. The subjects were excluded if they had: (i) a history of injury to the upper extremity in the past 3 months; (ii) a history of cervical or thoracic pathology; (iii) shoulder instability; (iv) a history of any spinal deformity or (v) a known history of severe cardiac anomalies.

\section{Procedure:}

The duration of study protocol was 4 weeks. Subjects from Group A and Group B were separately informed and explained about the study and the treatment procedures that they received. Patients were instructed not to skip the treatment and wear loose and comfortable clothing. A pre treatment reading was taken on day 0 and post treatment reading was taken at the end of $4^{\text {th }}$ week on Oxford Shoulder Score (OSS).

\section{Conventional Physiotherapy:}

Patients in both groups received conventional physiotherapy that included: Pectoralis minor stretch -3 times with 20 seconds hold, shoulder flexion with weight in sitting position, shoulder abduction with weight in sitting position and shoulder external rotation in side-lying position.

\section{Full Can Exercise:}

It is performed in sitting position. Patient was asked to abduct the arm to $90^{\circ}$ in scapular plane with shoulder in external rotation i.e. thumbs up position with weight belt tied around wrist. Then the arm is moved back to the starting position. Treatment was given 2 sets of 10 repetitions each for 5 times a week for 4 Weeks.

\section{Eccentric Training:}

It is a special eccentric muscle training model that activates only supraspinatus and deltoid muscle. An overhead pulley was mounted on the wall in which one end of the rope is attached to the weight belt. The weight belt is tied at wrist of affected hand of the patient. With help of pulley patient lifts the hand to the starting position i.e. $30^{\circ}$ of horizontal abduction with thumb pointing towards the ground. The patient is then asked to slowly lower the arm from the starting position. The exercise was done 3 sets of 15 repetitions each for 5 days in a week for 4 weeks.

\section{Oxford Shoulder Score:}

It was the outcome measure of this study. It consists of 12 questions related to pain and function. Each question has 5 ordinal responses from which patient need to choose 1 response for the particular question. Scores consist of 0-4 in which 0 means worst condition and 4 means best. The total score of the questionnaire is 60 and least is 0 that indicates severe shoulder problem.

The Source of data was Department of Physiotherapy, Rajeev Gandhi College, Bhopal.

\section{DATA ANALYSIS}

In the present study, data analysis was done using SPSS version 17 . Total 30 subjects were recruited for the study. The subjects were assessed using OSS. Pre and Post treatment readings were taken. As the number of samples in one group was 15 $(<50)$, normality of the data was determined using Shapiro-Wilk test in the study. The data was normally distributed and to compare the mean values within the groups paired t-test was used. Independent t-test was used to compare the mean value between Group A and B.

\section{RESULTS}

In the study, Subjects in Group A received Full Can Exercise along with conventional therapy and Group B subjects 
received Eccentric training along with conventional therapy for 4 weeks. The paired t-test done within Group A shows that subjects showed a significant improvement $(\mathrm{p}=0.01)$ post treatment. Similarly, in Group B Subjects showed a significant improvement $(\mathrm{p}=0.01)$ post treatment.

Later Independent $t-$ test was employed to compare the mean values of Group A and Group B which revealed that after comparing the mean values between the two groups, the post test reading showed a significant improvement in the OSS scores. After analyzing the data, we found that although the technique showed significant improvement within the group. Also, while comparing post-test values between the two groups, Group A showed more improvement as compared to Group B. It implies that full can exercise along with conventional therapy is more beneficial in the treatment of shoulder impingement syndrome and the result of group $\mathrm{A}$ is more effective.

Table 1: Comparison of mean value of Group A using paired t-test.

\begin{tabular}{|l|l|l|l|l|l|}
\hline Group A Variables & $\mathbf{N}$ & Mean & Standard deviation & t-value & Significant value P $<0.05$ \\
\cline { 1 - 4 } Pre OSS & 15 & 38 & 2.39 & 42.16 & 0.001 \\
\cline { 1 - 3 } Post OSS & 15 & 18.93 & 1.22 & & \\
\hline \multicolumn{5}{|c|}{ OSS -Oxford Shoulder Score }
\end{tabular}

Table 2: Comparison of mean values of Group $B$ using paired $t$-test.

\begin{tabular}{|l|l|l|l|l|l|}
\hline Group B Variables & $\mathbf{N}$ & Mean & Standard deviation & t-value & Significant value P $<\mathbf{0 . 0 5}$ \\
\hline Pre OSS & 15 & 36.33 & 3.37 & \multirow{2}{*}{25.89} & \multirow{2}{*}{0.001} \\
\hline Post OSS & 15 & 19.53 & 2.29 & & \\
\hline \multicolumn{5}{|c|}{ OSS -Oxford Shoulder Score }
\end{tabular}

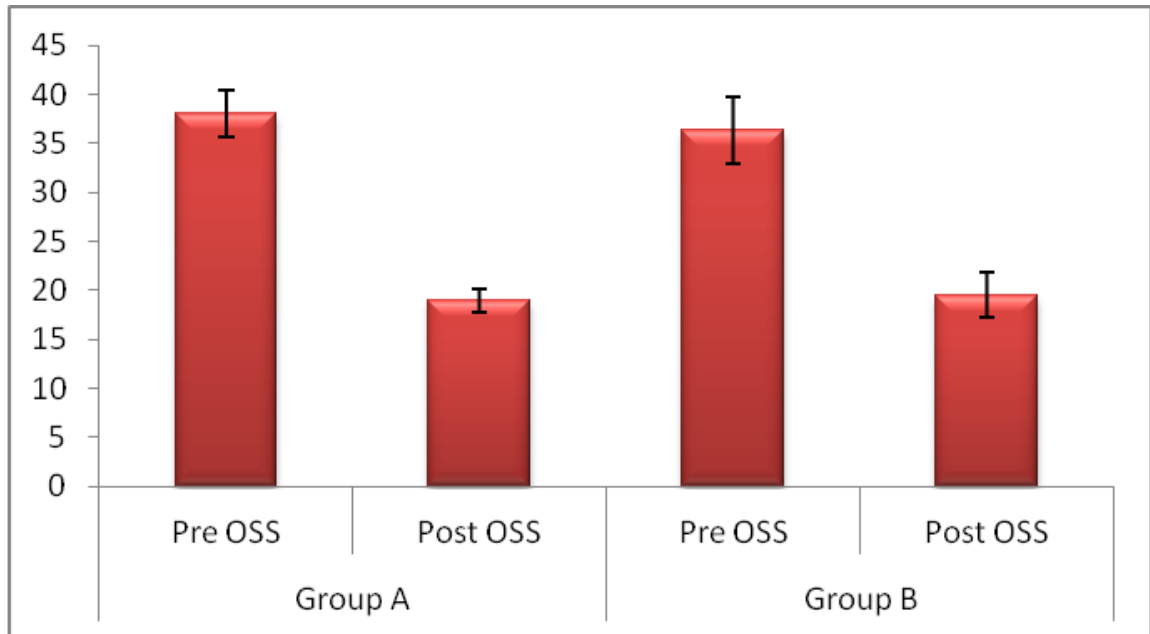

Graph 1: Graph showing the changes in the Oxford Shoulder Scores in Group A and Group B OSS -Oxford Shoulder Score

Table 3: Comparison of Mean values of Group A and Group B using independent t-test

\begin{tabular}{|l|l|l|l|l|l|}
\hline Variables of group A \& B & N & Mean & S. D & t=value & Significance two tailed \\
\hline PRE OSS & 30 & 37.16 & 2.88 & 1.561 & 0.130 \\
\hline POST OSS & 30 & 19.23 & 1.75 & -0.894 & 0.379 \\
\hline
\end{tabular}

\section{DISCUSSION}

After studying 30 subjects that were previously diagnosed with shoulder Impingement Syndrome with the age group of 25-45 years, the study was done on the basis of hypothesis testing. When the results were compared using the study variable, Oxford Shoulder Score, it was found that although both the techniques showed a significant improvement post treatment but Full Can exercise along with Conventional Physiotherapy was more effective than Eccentric training with Conventional Physiotherapy.

As explained by Neer $2005^{8}$ Shoulder Impingement syndrome is often caused by 
the impingement on the tendinous portion of rotator cuff muscle by the coracoacromial ligament and thus the symptoms arise. Tino and Hillis $2010^{24}$ had discussed how full can exercise is more beneficial in strengthening supraspinatus muscle in impingement syndrome. They have described that supraspinatus provides stability of humerus in the glenoid fossa and helps deltoid muscle during abduction. Supraspinatus is subjected to compression between coracoacromial arch and greater tuberosity of humerus while abducting the shoulder. Due to weakness or injury of rotator cuff, the subacromial space is reduced. So strengthening of supraspinatus is essential to improve shoulder stability and to minimize the effect of impingement. They have also discussed the effect of empty can exercise (which is the shoulder abduction in the scapular plane with the shoulder in internal rotation) and full can exercise effects. During Empty Can exercise, pain increased owing to the mechanical compression and impingement due to reduced subacromial space. Reduction in subacromial space occurs because empty can exercise is performed in $30^{\circ}$ scapular lane i.e. $30^{\circ}$ anterior to the frontal plane, with internal rotation maintained throughout the exercise and also during empty can exercise along with supraspinatus deltoid muscle activation is also observed that results in superior humeral head migration causing reduction in subacromial space. Internal rotation results in reduction in subacromial space. In contrast to this, during full can exercise shoulder is abducted in $30^{\circ}$ scapular plane with shoulder in external rotation. This strengthens the supraspinatus effectively without increasing the compression and impingement by reducing the subacromial space.

We had used eccentric training along with conventional physiotherapy in order to improve healing and also to strengthen the supraspinatus muscle with load. It increases the endurance of muscle ${ }^{23}$ to with stand the stress it is subjected to both the techniques i.e. full can and eccentric training showed significant improvement in pain reduction and increasing functional abilities of the patients in our study. However, full can showed more improvement than eccentric training. This is because full can emphasizes more on supraspinatus muscle. It strengthens only supraspinatus alone while eccentric training puts more loads on supraspinatus but it also activates deltoid muscle. Thus, according to above discussion, it is suggested that full can exercise is more beneficial than eccentric training.

\section{Limitations of the Study:}

The sample size was limited because only chronic shoulder impingement syndrome patients were included in the study. Subjects had to be motivated to continue with the study for 4 weeks and explained about the long term benefits. Study protocol was for 4 weeks. A short study could also be performed.

\section{Future scope of the Study:}

The study can be performed on different group of population. For more accurate results, the sample size can be increased. Subjects with shoulder impingement syndrome due to other known causes can be included in the study.

\section{CONCLUSION}

On comparing the data within the group A which received full can exercise along with conventional physiotherapy and group B which received eccentric training along with conventional physiotherapy, it was found that both the groups showed significant reduction in the symptoms of Shoulder impingement syndrome. However, when the data between the two groups was compared, it was inferred that full can exercise along with conventional physiotherapy is more beneficial in reducing symptoms of shoulder impingement syndrome. Thus, we accept the alternate hypothesis and conclude that there is a significant difference between the effect of full can exercise and eccentric training on 
quality of life in patients with shoulder impingement syndrome.

\section{Acknowledgement: None}

\section{Conflict of Interest: None}

\section{Source of Funding: None}

\section{Ethical Approval: Approved}

\section{REFERENCES}

1. Levangie PK, Norkin CC. Joint structure and function: a comprehensive analysis. FA Davis; 2011 Mar 9.

2. Veeger HE, Van Der Helm FC. Shoulder function: the perfect compromise between mobility and stability. Journal of biomechanics. 2007 Jan 1;40(10):2119-29.

3. Gray H. Anatomy of the human body. Philadelphia: Lea \& Febiger, 1918; Bartleby. com, 2000.

4. Codman EA, Akerson IB. The pathology associated with rupture of the supraspinatus tendon. Annals of surgery. 1931 Jan;93(1):348.

5. Ellis $\mathrm{H}$, Mahadevan V. Clinical anatomy: applied anatomy for students and junior doctors. Wiley-Blackwell; 2018 Nov 12.

6. Salata MJ, Nho SJ, Chahal J, Van Thiel G, Ghodadra N, Dwyer T, Romeo AA. Arthroscopic anatomy of the subdeltoid space. Orthopedic reviews. 2013 Jul 24;5(3).

7. van der Windt DA, Thomas E, Pope DP, de Winter AF, Macfarlane GJ, Bouter LM, Silman AJ. Occupational risk factors for shoulder pain: a systematic review. Occupational and environmental medicine. $2000 \mathrm{Jul}$ 1;57(7):433-42.

8. Neer II CS. Anterior acromioplasty for the chronic impingement syndrome in the shoulder. Journal of Bone and Joint Surgery. 2005 Jun 1;87(6):1399.

9. Burke WS, Vangsness CT, Powers CM. Strengthening the supraspinatus: a clinical and biomechanical review. Clinical Orthopaedics and Related Research®. 2002 Sep 1;402:292-8.

10. Weevers HJ, van der Beek AJ, Anema JR, van der Wal G, van Mechelen W. Workrelated disease in general practice: a systematic review. Family practice. 2005 Feb 14;22(2):197-204.
11. Luime JJ, Koes BW, Hendriksen IJ, Burdorf A, Verhagen AP, Miedema HS, Verhaar JA. Prevalence and incidence of shoulder pain in the general population; a systematic review. Scandinavian journal of rheumatology. 2004 Mar 1;33(2):73-81.

12. Perry J. Normal upper extremity kinesiology. Physical Therapy. 1978 Mar 1;58(3):265-78.

13. Starr M, Kang H. Guest CME: Recognition and Management of Common Forms of Tendinitis and Bursitis. Canadian Journal of Cme. 2001;13(6):155-63.

14. Smith DL, Campbell SM. Painful shoulder syndromes. Journal of general internal medicine. 1992 May 1;7(3):328-39.

15. Middleton WD. Ultrasonography of the shoulder. Radiologic Clinics of North America. 1992 Sep;30(5):927-40.

16. Zlatkin MB, Iannotti JP, Roberts MC, Esterhai JL, Dalinka MK, Kressel HY, Schwartz JS, Lenkinski RE. Rotator cuff tears: diagnostic performance of MR imaging. Radiology. 1989 Jul;172(1):223-9.

17. Neumann $\mathrm{CH}$, Holt RG, Steinbach LS, Jahnke Jr AH, Petersen SA. MR imaging of the shoulder: appearance of the supraspinatus tendon in asymptomatic volunteers. AJR. American journal of roentgenology. 1992 Jun;158(6):1281-7.

18. Farley TE, Neumann CH, Steinbach LS, Jahnke AJ, Petersen SS. Full-thickness tears of the rotator cuff of the shoulder: diagnosis with MR imaging. AJR. American journal of roentgenology. $1992 \mathrm{Feb}$;158(2):347-51.

19. Kneeland JB, Middleton WD, Carrera GF, Zeuge RC, Jesmanowicz AN, Froncisz W, Hyde JS. MR imaging of the shoulder: diagnosis of rotator cuff tears. American Journal of Roentgenology. 1987 Aug $1 ; 149(2): 333-7$.

20. Fongemie AE, Buss DD, Rolnick SJ. Management of shoulder impingement syndrome and rotator cuff tears. American family physician. $1998 \mathrm{Feb}$;57(4):667-74.

21. Clement ND, Nie YX, McBirnie JM. Management of degenerative rotator cuff tears: a review and treatment strategy. Sports Medicine, Arthroscopy, Rehabilitation, Therapy \& Technology. 2012 Dec;4(1):48.

22. Loppini M, Maffulli N. Conservative management of tendinopathy: an evidencebased approach. Muscles, ligaments and tendons journal. 2011 Oct;1(4):134. 

impingement syndrome.

23. Camargo PR, Alburquerque-Sendín F, Salvini TF. Eccentric training as a new approach for rotator cuff tendinopathy: review and perspectives. World journal of orthopedics. 2014 Nov 18;5(5):634.

24. Tino D, Hillis C. The full can exercise as the recommended exercise for strengthening the supraspinatus while minimizing impingement. Strength \& Conditioning Journal. 2010 Oct 1;32(5):33-5.

25. Jain S, Shukla Y, Shah M. To study the effect of empty can vs full can exercise in chronic supraspinatus tendonitis-a comparative study. Indian journal of physical therapy. 2015 Jun 30;3(1).

26. Olley LM, Carr AJ. The use of a patientbased questionnaire (the Oxford Shoulder Score) to assess outcome after rotator cuff repair. The Annals of The Royal College of Surgeons of England. 2008 May;90(4):32631.

27. Littlewood C, Ashton J, Chance-Larsen K, May S and Sturrock, B. Exercisefor rotator cuff tendinopathy: a systematic review. Physiotherapy 2012;98:101-109.

28. Bang MD. and Deyle GD. Comparison of supervised exercise with and without manual physical therapy for patients with shoulder impingement syndrome. Journal of Orthopaedic and Sports Physical Therapy 2000; 30:126-137.

29. Ludewig P, Borstad J. Effects of a home exercise programme on shoulder pain and functional status in construction workers. $\mathrm{J}$ Occ Envi Med 2003; 60:841-9.

30. Dawson J, Rogers K, Fitzpatrick R, Carr A. The Oxford shoulder score revisited. Archives of orthopaedic and trauma surgery. 2009 Jan 1;129(1):119-23.

How to cite this article: Jain K. Effectiveness of full can exercise and eccentric training on quality of life in patients with shoulder impingement syndrome. Int J Health Sci Res. 2022; 12(2):181-187. DOI: https://doi.org/10. 52403/ijhsr.20220225 